\title{
Üniversite Öğrencilerinin Gözüyle Üniversite Kavramı
}

\author{
DOI: 10.26466/opus.786247
}

*

\author{
Nesip Demirbilek* \\ * Dr. Öğr. Üyesi, Bingöl Üniversitesi \\ E-Posta: ndemirbilek@bingol.edu.tr \\ ORCID: $\quad \underline{0000-0001-5133-7111}$

\section{Öz}

Bu araştırmanın amacı üniversite öğrencilerinin üniversite kavramı hakkındaki düşüncelerini metaforlar aracılığı ile nasıl kavramsallaştırdıklarını ortaya koymaktır. Araştırmada nitel araştırma yöntemlerinden fenomonolojik desen, çalışma grubunun belirlenmesinde ise kolay ulaşılabilir durum örneklemesi kullanılmıştır. Araştırmada 2019-2020 eğitim-öğretim yılında Bingöl Üniversitesinde öğrenim gören toplam 539 üniversite öğrencisi yer almıştır. Araştırmada öğrencilere metafor cümlesi online ortamda mail olarak gönderilmiştir. Verilerin analizinde "içerik analizi" tekniğinden yararlanılmıştır. Araştırma sonuçlarına göre öğrenciler tarafindan en fazla "her çeşit insanın olduğu yer" kategorisinde metafor üretilmiştir $(f=78)$. Öğrencilerin ürettiği metaforlar frekans sayısı bakımından; her çeşit insanın olduğu yer, tecrübe kazandıran yer, yeni bir hayatın başlangıcı olan yer, bilgilerin kaynăğ olan ve yayıldığı yer, hayatına yön verdiğin yer, zor olan yer, emek vermen gereken yer, eğlenceli olan yer, gerçek hayatın simülasyonu olan yer, bilgi sahibi olduğun yer, farklılaşıp yeni bakış açıları kazandı̆̆ın yer, eşsiz ve güzel olan yer, özgürlüğ̈̈̈ başladığı yer, yaşam alanı olan yer, aydınlanmanın yaşandı ̆̆ 1 yer, değerli ve mecburi olan kurum, eğitici olan kurum, keşiflerin yapıldığı yer, hayal kırıklı̆̆ının yaşandı̆̆ı yer, hayallerin gerçekleştiği yer, heyecanın yaşandığı yer, maddi zorlukların yaşandığı yer ezberi zorunlu kılan sıradan bir yer, gizliliğin olduğu yer, boşluğa düşülen yer yer gibi toplam 25 kategori başlı̆̆ı altında yer aldığı görülmüştür.

Anahtar Kelimeler: Üniversite, Metafor, Üniversite Öğrencisi, 


\title{
University Concept in the Eyes of University Students
}

\begin{abstract}
The aim of this research is to reveal how university students conceptualized their thoughts on the concept of university through metaphors. In the research, the phenomenological pattern, which is one of the qualitative research methods, and the easily accessible case sampling were used to determine the study group. The research included 539 university students studying at Bingöl University in the 2019-2020 academic year. In the study, the metaphor sentence was sent to the students as an online mail. "Content analysis" technique was used in the analysis of the data. According to the results of the research, metaphors were produced mostly by the students in the category of "where there are all kinds of people" $(f=78)$. Metaphors produced by students in terms of number of frequencies, respectively; the place of all kinds of people, the place that gives experience, the place of the beginning of a new life, the place where the information is spread and spread, the place where you direct your life, the place where it is difficult, the place where you have to work, the place where it is fun, the simulation of real life, the knowledge owner where you are, where you differentiate and gain new perspectives, the place that is unique and beautiful, the place where freedom begins, the place of living, the place of enlightenment, the institution that is valuable and compulsory, the educational institution, the place of discoveries, the place of disappointment, the realization of dreams. It was observed that the place was under 25 categories, such as the place where the excitement was experienced, the place where the financial difficulties were experienced, an ordinary place that makes memorization mandatory, the place where there is privacy, the place falling into space.
\end{abstract}

Keywords: University, Metaphor, University Student, 


\section{Giriş}

Ülkelerin ekonomik ve sosyal gelişmelerinde nitelikli insan gücü durumu, ülkeler arasındaki rekabeti arttıran belirleyici ögelerdendir. Bireylere nitelik, kazandırılmasında eğitimin, özellikle üniversitelerin önemli bir rolü vardır. Yükseköğretim nitelikli insan gücü yetiştirme görevinin yanı sıra bu kişilerin elde ettiği gelir düzeyinin artmasına bunun sonucunda sosyal kalkınmanın gelişimine katkıda bulunmaktadır (Uysal ve Ersun Aydemir, 2016; Kurt ve Gümüş, 2015). Üniversiteler toplumun ihtiyaç duyduğu nitelikli insan gücünü karşılamayla birlikte, kültür aktarımını sağlama, gerçekleştirilen bilimsel araştırmalar yoluyla yeni bilgi ve teknolojiler üretme ve bunlar aracilı̆̆yla toplumun sorunlarını çözme, toplumların bilimsel, ekonomik, teknolojik, sosyal ve kültürel gelişmelerini sağlama, hayat boyu öğrenme olanağ1 ve toplum hizmetleri sunma amacıyla kurulmuştur (Şahin, Zoraloğlu ve Fırat, 2011; Çetinsaya, 2014). Üniversiteler özerk olduğundan dolay1, tüm düşüncelerin herhangi bir baskı olmaksızın özgürce tartışılabildiği, toplum yararına bilgi üretildiği, paylaşan ve yayan bağımsız bir öğretim ve araştırma örgütleri olarak tanımlanmaktadır (Ortaş, 2004). Üniversiteler eğitim öğretim etkinlikleri gerçekleştiren, bilimsel araştırma ve elde edilen sonuçları bilimsel yayınlar aracılı̆̆ıyla paylaşan ve topluma hizmet görevini yerine getiren örgütler olarak aktarılmaktadır. Ayrıca üniversiteler üst düzey bilgi beceri ve yetenek eğitiminin verildiği eğitim kademeleridir (Açıkgöz, 2012)

Alan yazındaki çalışmalar incelendiğinde; dünyadaki üniversitelerin kronolojik olarak beş dönem içerisinde sinıflandırıldığı görülmektedir (Antalyall, 2007). Bunlar; Orta Çağ Avrupa'sında kurulan ilk üniversiteler, Rönesans Dönemi üniversiteleri, 19. Yüzyıl Grandes Ecoles ve Alman Üniversiteleri ile 20. Yüzyıl Üniversiteleridir. Türkiye' deki üniversiteler ise tarihsel olarak üst başlıkları, Cumhuriyet ilan edilmeden önce ve Cumhuriyet ilan edildikten sonra şeklinde iki zaman diliminde değerlendirmek uygun olacaktır. Cumhuriyet ilan edildikten sonra yükseköğretimde büyük ve hızlı gelişmeler yaşanmıştır. Yükseköğretimde meydana gelen bu gelişmeler, Cumhuriyet ilan edildikten 1946 yılına kadar, 1946 yılından Yükseköğretim Kurulu'nun (YÖK) kuruluşu olan 1981 yllına kadar ve YÖK'ün kurulmasından günümüze şeklinde üç dönem olarak incelenebilir (Kılıç, 1999). 
Üniversiteler, özgürlüğün, aklın, bilimin ve eleştirinin egemen olduğu temel kurumlardır. Özgürlük olmadığı bir yerde aklın egemenliğinden söz etmek doğru değildir ve özgür olmayan aklın gerçek anlamda bilim üretmesi mümkün değildir. Bugün üniversitelerimiz bilimsel düşünme gücüne sahip ve aklını kullanan bireyleri ne ölçüde yetiştirmektedir? Bir okul olarak üniversite, öğrencileri tarafından nasıl algılanmaktadır (Demirtaş ve Çoban, 2011).

Üniversiteler ayrıca bir ülkenin kalkınmasında ve gelişmesinde etkili olan temel kurumlardır. Üniversite, ülkenin ihtiyaç duyduğu nitelikli insan gücünü yetiştirmek, evrensel boyutta yaşam düzeyinin gelişimine ve aydınlanmaya katkı sağlamak gibi görevleri vardır. Üniversiteler, hakikati arayan, bilim üreten, onu yayan ve onu kullanan kurumlardır (Timur, 2000, s.13).

Ülkemizde yükseköğretime erişim yükseköğretimle ilgili sorunların başında gelmektedir. Özellikle 20. yüzyılın ortalarından itibaren insan sermayesi kuramında belirtildiği üzere toplumsal ve bireysel gelişimin artırılmasinda üniversitelerin etkisinin yüksek düzeyde olduğu inancı üniversitelere olan isteği giderek arttırmıştır (Özoğlu, 2011). Ülkemizde özellikle son yirmi yılda kamu ve vakıf yükseköğretim örgütlerinin sayısı artmıştır. Türkiye Yükseköğretim Sisteminde son yıllarda niceliksel olarak meydana gelen artışa paralel olarak üniversitelerin niteliğindeki değişimin gerçekleşmediği görülmektedir. Ayrıca toplumun üniversiteye verdiği önem ve gösterdiği ilgi giderek artarken, diğer yandan üniversitelerde yaşanan sorunların da her geçen gün çeşitlenerek arttı̆̆1 söylenmektedir (Demirtaş ve Çoban, 2011). Bu çerçevede öncelikle üniversite kavramının öğrencilerin zihninde oluşturduğu algının daha iyi anlaşılabilmesi ve bu sayede daha iyi açıklanabilmesi için metafor çalışmalarının yapılması önem arz etmektedir.

\section{Araştırmanın Amacı}

Çalışmanın amacı üniversite öğrencilerinin üniversite kavramı hakkındaki düşüncelerini metaforlar aracılığı ile nasıl kavramsallaştırdıklarını ortaya koymaktır. Bu bağlamda aşağıda belirtilen araştırma sorularının cevapları aranmıştır. 
1. Üniversite öğrencilerinin cinsiyetlerine göre üniversite kavramına yönelik metaforları nelerdir?

2. Üniversite kavramına yönelik üretilen metaforlar, benzer özellikler bakımından hangi kategoriler altında toplanmaktadır.

\section{Yöntem}

\section{Araştırmanın Modeli}

Araştırmada, Bingöl Üniversitesinin çeşitli bölümlerinde okuyan üniversite öğrencilerinin görüşleri doğrultusunda üniversite kavramına yüklenmiş olan anlamlar derinlemesine incelendiği için nitel araştırma desenlerinden olgubilim (fenomenolojik) deseni kullanılmıştır. Farkında olduğumuz fakat derinlemesine ve nedenleri ile belirlemek istediğimiz olguların aydınlatılmasında olgubilim deseni kullanılmaktadır (Yıldırım ve Şimşek, 2013). Fenomenoloji; daha çok insanın iç dünyasını ve onların bilinç yapılarını anlamaya çalışan bir araştırma desenidir (Mayring, Gümüş ve Durgun, 2011). Olgu bilim ile bize çok yabancı olmayan fakat kesinliği hakkında da bilgi sahibi olmadığımız olguları, derinlemesine inceleme fursatı bulur ve zengin söylemlerle yorumlamada bulunma olanağı sağlarız (Yaman, Mermer ve Mutlugil, 2009; Sönmez ve Alacapınar, 2011). Bu bağlamda bireylerin bir olguyu nasıl algıladıkları, açıkladıkları, hatırladıkları ve bu olguyu insanlara aktarmak için nasıl bir dil kullandıkları araştırılır (Patton, 2014).

\section{Araştırmanın Çalışma Grubu}

Çalışma grubunun belirlenmesinde kolay ulaşılabilir durum örnekleme yöntemlerinden random örnekleme tekniği kullanılmıştır. Bu teknik ile katılımcların belirlenmesinde genel olarak araştırmacının kolay ulaşacağı kişilerden yararlanılmaktadır (Yıldırım ve Şimşek, 2013). Bu çalışmanın katılımcıları Bingöl Üniversitesinin çeşitli bölümlerinde okuyan üniversite öğrencileri olarak belirlenmiş ve 549 üniversite öğrencisine ulaşılmıştır. Ancak üniversite kavramına ilişkin hatalı metafor oluşturan 10 form elenmiş, sonuç olarak 539 kişiden oluşmuştur. 
Tablo 1. Araştırmaya katılan öğrencilere ait demografik bilgiler

\begin{tabular}{llll}
\hline Değiş̧kenler & Kategori & $\mathbf{N}$ & $\mathbf{\%}$ \\
\hline \multirow{2}{*}{ Cinsiyet } & Kadın & 423 & 78,8 \\
& Erkek & 116 & 21,2 \\
\hline & İngilizce & 87 & 16,2 \\
& Tarih & 67 & 12,6 \\
& Türk Dili ve Edebiyatı & 84 & 15,7 \\
& Kürt Dili ve Edebiyatı & 19 & 3,5 \\
Bölümler & Zaza Dili ve Edebiyatı & 21 & 3,8 \\
& Sosyoloji & 76 & 14,2 \\
& Felsefe & 91 & 17 \\
& Moleküler Biyoloji & 22 & 3,9 \\
& Sosyal Hizmet & 72 & 13,1 \\
\hline Toplam Öğrenci Sayısı & & 539 & 100 \\
\hline
\end{tabular}

\section{Verilerin Toplanmast}

Bingöl Üniversitesinin çeşitli bölümlerinde okuyan üniversite öğrencilerinin üniversite kavramına ilişkin algılarına metafor yoluyla ulaşmayı amaçlayan bu araştırmada online ortamda iki bölümden oluşan bir adet form oluşturulmuştur. Birinci bölümde demografik özelliklerin sorulduğu kişisel bilgi formu yer almaktadır. İkinci bölümde ise katılımclardan "Üniversite gibidir/benzemektedir, çünkü ......."cümlesini tamamlamaları istenmiştir. Ayrıca bu bölümde bazı kavramların metaforları hakkında açıklama yapılarak örnekler verilmiş ve bu doğrultuda katılımcılardan tek bir metafor oluşturarak nedenini belirtmeleri istenmiştir (Kılcan 2017). Hazırlanan formlar online olarak gönderilmiştir.

\section{Verilerin Analizi}

Araştırmada elde edilen verilerin analizinde içerik analizi kullanılmıştır. İçerik analizinde toplanan veriler, kodlama ve ayıklama, kategori geliştirme aşaması, geçerlik ve güvenirliği sağlama aşaması ve bulguların yorumlanması olmak üzere dört aşamada analiz edilmektedir (Saban, 2008). İlk etapta üniversite öğrencilerinin metaforları incelenmiştir. "Üniversite" kavramını metafor olarak açiklayamayan veriler elenmiştir $(\mathrm{f}=10)$. Ayılklama aşamasının ardından ikinci aşama olarak verileri kavramsal kategorilere ayırma işlemi yapılmıştır.

İkinci etapta, öğrenciler tarafından üretilen metaforlar üniversite kavramılla ilgili benzer özellikler çerçevesinde gruplanmış ve kategoriler oluşturulmuştur. 


\section{Geçerlik ve Güvenirlik}

Öncelikle, her bir görüşme formu öğrenciler için cinsiyet değişkenine göre ayrılmış, kadınlar için K1, K2... erkekler için ise E1, E2...şeklinde kodlanmıştır. Görüşme formunda yer alan metafor cümlesine verilen yanıtlar araştırmacı tarafından titizlikle irdelenmiş ve tümevarımcı bir yaklaşımla, önceden belirlenen bir kod içeriği olmadan ifadelerin özüne bağlı kalınarak kodlamalar yapılmıştır. Kodlama yapılırken ifade sıklığının belirlenmesine dikkat edilmiştir. Kodlar bir araya getirilerek benzerlikleri ve farklılıkları incelenmiş, birbirine benzer kodlar arasında ortak yönler bulunarak kategoriler oluşturulmuştur (Yıldırım ve Şimşek, 2013).

Üçüncü etap olan geçerlik ve güvenirlik için araştırmada belirlenen toplamda 25 kategori altında verilen metaforlar, başka bir uzmana gönderilmiştir. Hiçbir metaforu dışarıda bırakmayacak şekilde metaforları, kategorilere yerleştirmesi istenmiştir. Daha sonra uzmanın yaptığı sınıflama ile araştırmacı tarafından yapılmış sınıflamanın karşılaştırması yapılmıştır. İstenilen düzeyde bir güvenilirlik sağlamak için nitel çalışmalarda uzman ve araştırmacı değerlendirmeleri arasındaki uyumun \%90 ve üzeri olması gerekmektedir (Saban, 2008). Yapılan bu araştırmanın güvenirliği (Güvenirlik= Görüş birliği/Görüş birliği+Görüş ayrılığ1 x 100) ile hesaplanmış (Miles ve Huberman, 1994) ve \% 91 oranında bir uzlaşma olduğu sonucuna ulaşılmıştır.

Dördüncü etap olan yorumlama aşamasında öğrenciler tarafından oluşturulan metafor sayıları frekans olarak hesaplanmıştır.

\section{Bulgular}

\section{Birinci Alt Probleme İlişkin Bulgular}

Tablo 2. Öğrencilerin cinsiyetlerine göre üniversite kavramına yönelik ürettikleri metaforlar

\begin{tabular}{|c|c|c|c|c|c|}
\hline Metafor ad1 & $\mathrm{f}$ & $\mathrm{f}$ & Metafor ad 1 & $\mathrm{f}$ & $\mathrm{f}$ \\
\hline & Kadın & Erkek & & Kadın & Erkek \\
\hline Hayat & 33 & 7 & Kader & 1 & \\
\hline Kitap & 15 & 3 & Akademik başarı & 1 & \\
\hline $\mathrm{Ev}$ & 8 & 3 & Kalkan & 1 & \\
\hline Bilim yuvası & 5 & 5 & Kadın & 1 & \\
\hline Özgürlük & 8 & 1 & Altın bilezik & 1 & \\
\hline Ağaç büyütme & 4 & 3 & Amazon ormanı & 1 & \\
\hline Dünya & 7 & & Kalem & 1 & \\
\hline El feneri & 3 & 3 & Ayakta durabilmek & 1 & \\
\hline
\end{tabular}




\begin{tabular}{|c|c|c|c|c|}
\hline Merdiven basamakları & 4 & 2 & Kardelen & 1 \\
\hline Gökkuşağı & 4 & 2 & Kapitalist sistem & 1 \\
\hline Tarla & 4 & 2 & Akılll telefon & 1 \\
\hline Okyanus & 5 & & Kazan & 1 \\
\hline Yol & 4 & 1 & Kelebek & 1 \\
\hline Aşk & 3 & 2 & Ana & 1 \\
\hline Bahçe & 3 & 2 & Alışkanlık & 1 \\
\hline Kütüphane & 4 & & Açık büfe & 1 \\
\hline Ansiklopedi & 4 & & Kita & 1 \\
\hline Survivor & 4 & & Kimlik & 1 \\
\hline Bilgisayar & 4 & & Asker ocağ1 & 1 \\
\hline Deniz & 3 & 1 & Kişilik testi & 1 \\
\hline Pusula & 3 & 1 & Konser alanı & 1 \\
\hline Gelecek & 3 & 1 & Araba & 1 \\
\hline Çiçek bahçesi & 3 & 1 & Arama motoru & 1 \\
\hline Ülke & 3 & 1 & Kozmopolit & 1 \\
\hline Meyve & 3 & 1 & Kum saati & 1 \\
\hline Arıkovanı & 2 & 2 & Kuluçkadaki tavuk & 1 \\
\hline Ayna & 2 & 2 & Kumbara & 1 \\
\hline Fabrika & 2 & 2 & Bahar & 1 \\
\hline Harita & 3 & & Kurtlar sofrasi & 1 \\
\hline Kendi benliğini tanıma & 3 & & Açık cezaevi & 1 \\
\hline Kamp alanı & 3 & & Kuş & 1 \\
\hline Aile & 3 & & Ayrıcalığa sahip olmak & 1 \\
\hline Dönüm noktası & 3 & & İnsan fabrikası & 1 \\
\hline Toprak & 3 & & İnsan pazarı & 1 \\
\hline Hayat sinavi & 3 & & Bilgi hazinesi & 1 \\
\hline Hayvanat bahçesi & 3 & & Bilgi merkezi & 1 \\
\hline Karınca yuvası & 2 & 1 & Borç & 1 \\
\hline Kafes & 2 & 1 & Sosyal bir kafe & 1 \\
\hline Meyve veren bir ağaç & 2 & 1 & Sorumluluk & 1 \\
\hline Heykeltıraş & 2 & & Gencin ikinci sosyal hayatı & 1 \\
\hline Çikolata & 2 & & İlaç & 1 \\
\hline Işık & 2 & & Süpermarket & 1 \\
\hline Sevgi & 2 & & Macera & 1 \\
\hline Çıkmaz bir sokak & 2 & & Bahçıvan & 1 \\
\hline Merdiven & 2 & & Bakış açıSı & 1 \\
\hline Anahtar & 2 & & Başarılı öğrenci & 1 \\
\hline Keşfedilmemiş gezegen & 2 & & Marangoz & 1 \\
\hline Gonca gül & 2 & & Bilim dünyası & 1 \\
\hline Tarım & 2 & & Medeniyet & 1 \\
\hline Gezi & 2 & & Medrese & 1 \\
\hline Deniz feneri & 2 & & Memleket & 1 \\
\hline Işık & 2 & & Menfaat & 1 \\
\hline Güneş & 2 & & Zor & 1 \\
\hline Orman & 2 & & Zorluklara temel atılan ilk yer & 1 \\
\hline Uzay & 2 & & İnternet sitesi & 1 \\
\hline Yeni hayat & 2 & & Beyin & 1 \\
\hline
\end{tabular}




\begin{tabular}{|c|c|c|c|c|}
\hline Tren & 2 & & Bilim & 1 \\
\hline Gerçekler & 1 & 1 & Çölde bir serap & 1 \\
\hline $\mathrm{Su}$ & 1 & 1 & Yeni alınmış bir ev & 1 \\
\hline Temiz bir sayfa & 1 & 1 & Eğlencenin son aşaması & 1 \\
\hline $\begin{array}{l}\text { Hayatın en güzel ve } \\
\text { rahat dönemi }\end{array}$ & 1 & 1 & $\begin{array}{l}\text { Güzelliğe ve kötülüğe açılan } \\
\text { iki gizli kapı }\end{array}$ & 1 \\
\hline Hayatın kendisi & 1 & 1 & Çıkmazdan önceki son tünel & 1 \\
\hline Hayvan çiftliği & 1 & 1 & İmtihan yeri & 1 \\
\hline Kilavuz & 1 & 1 & Mevsim & 1 \\
\hline Kâinat & 1 & 1 & Milat & 1 \\
\hline Kalp & 1 & 1 & Çiftlik & 1 \\
\hline Yaşam & 1 & 1 & Nebula & 1 \\
\hline Savaş meydanı & 1 & 1 & Navigasyon & 1 \\
\hline Huzur & 1 & 1 & Mutluluk & 1 \\
\hline Rüya & 1 & 1 & Muz & 1 \\
\hline Hapishane & 1 & 1 & Mükemmel & 1 \\
\hline Cezaevi & 1 & 1 & Müze & 1 \\
\hline Kuş yuvası & 1 & 1 & Nar & 1 \\
\hline Aritma tesisi & & 2 & Engelli parkur & 1 \\
\hline Gerçek yaşam & & 1 & En rahat yillar & 1 \\
\hline Doğduğun ev & & 1 & Evrim & 1 \\
\hline İnsan & & 1 & Dağın zirvesi & 1 \\
\hline Meyve bahçesi & & 1 & Dipsiz kuyu & 1 \\
\hline Merdivenin ilk basamağ1 & & 1 & İlkokul & 1 \\
\hline Meşale & & 1 & Dibi kum, çakıl dolu okyanus & 1 \\
\hline Çorba & & 1 & Disko topu gibi rengârenk, & 1 \\
\hline Mecburiyetten yediğin yemek & & 1 & $\begin{array}{l}\text { Kurak bir toprağa özveri ile } \\
\text { yetiştirilen ağaçlar }\end{array}$ & 1 \\
\hline Bilim kütüphanesi & & 1 & Dünyaya yeniden gelmek & 1 \\
\hline Bilgi & & 1 & Dünya'nın küçük hâli & 1 \\
\hline $\begin{array}{l}\text { Bir çocuğun elindeki } \\
\text { dondurma }\end{array}$ & & 1 & $\begin{array}{l}\text { Dünyaya açılan yeni bir } \\
\text { pencere }\end{array}$ & 1 \\
\hline $\begin{array}{l}\text { Bilginin ve kültürün birleştiği } \\
\text { yer }\end{array}$ & & 1 & $\begin{array}{l}\text { Zirveye ulaşmaya } \\
\text { yardımcı merdiven }\end{array}$ & 1 \\
\hline Boş & & 1 & Fantastik-gerilim filmi & 1 \\
\hline Özgürlüğün başlangıcı & & 1 & Fakirlik & 1 \\
\hline Okul & & 1 & Festival & 1 \\
\hline Pazar & & 1 & Gelişme & 1 \\
\hline Kozmopolit şehir & & 1 & Gençlik festivali & 1 \\
\hline Bulmaca & & 1 & Genel ağ & 1 \\
\hline Büyük bir sosyal kurum & & 1 & Gelişim & 1 \\
\hline Hayal kırıklığı & & 1 & Gezen bir kütüphane & 1 \\
\hline Osmanlı devleti & & 1 & Gezgin & 1 \\
\hline Süreç & & 1 & Gida & 1 \\
\hline Öğretmen & & 1 & Gizemli bir yer & 1 \\
\hline Antrenman & & 1 & Boş defter & 1 \\
\hline Akvaryum & & 1 & Bukalemun & 1 \\
\hline Yokuş & & 1 & Çay & 1 \\
\hline
\end{tabular}




\begin{tabular}{|c|c|c|c|c|}
\hline Bataklık & & 1 & İğneyle kuyu kazmak & 1 \\
\hline Belediye & & 1 & Gökyüzü & 1 \\
\hline Ayrı ülkeler & & 1 & Gül & 1 \\
\hline Avize & & 1 & Olgun ağaç & 1 \\
\hline Bağımsız bir ülke & & 1 & Olgunluk çağ1 & 1 \\
\hline Küçük bir dünya & & 1 & Büyük ev & 1 \\
\hline Maden ocağ & & 1 & Büyükşehir & 1 \\
\hline Maraton & & 1 & Cehennem & 1 \\
\hline Ressamın firça darbeleri & & 1 & Cennet & 1 \\
\hline $\begin{array}{l}\text { Her elementin yer aldığı } \\
\text { bir maden }\end{array}$ & & 1 & $\begin{array}{l}\text { Farklı harflerin bir araya } \\
\text { gelerek oluşturduğu kelime }\end{array}$ & 1 \\
\hline Hazine haritası & & 1 & Hayal & 1 \\
\hline $\begin{array}{l}\text { Sinursiz kitap bulunan } \\
\text { bir kütüphane }\end{array}$ & & 1 & $\begin{array}{l}\text { Firsatları değerlendirmenin } \\
\text { en iyi ortamı }\end{array}$ & 1 \\
\hline Sirk & & 1 & Ömür & 1 \\
\hline Tadı kötü yemek & & 1 & Güvercin & 1 \\
\hline Yaşam tarzı & & 1 & Hayata atılan ilk adım & 1 \\
\hline Yatırım & & 1 & Hayata başlamak & 1 \\
\hline Yeni keşfedilmiş gezegen & & 1 & Google & 1 \\
\hline Sosyalleşme & & 1 & Palyaço & 1 \\
\hline Yolculuk & & 1 & Panaptikon & 1 \\
\hline İnsan & & 1 & Papağan & 1 \\
\hline Eğitim yuvası & & 1 & Para kazanma & 1 \\
\hline Hayatın gerçek yüzü & 1 & & Adrenalin & 1 \\
\hline Hayatın yeni bir yolu & 1 & & Okuldan çok daha fazlası & 1 \\
\hline $\begin{array}{l}\text { Hayatta olgunlaşma ve } \\
\text { yoğrulma evresi }\end{array}$ & 1 & & $\begin{array}{l}\text { Hayallere giden yolda } \\
\text { durağa gelen otobüs }\end{array}$ & 1 \\
\hline $\begin{array}{l}\text { Yaşadığımız dünyanın } \\
\text { dışında, başka bir evren }\end{array}$ & 1 & & $\begin{array}{l}\text { Hayal kırıklıklarına uğranan } \\
\text { bir mekân }\end{array}$ & 1 \\
\hline Timarhane & 1 & & Hayat tecrübesi & 1 \\
\hline Ufka açlan bir kapı & 1 & & Pembe hayaller & 1 \\
\hline Umut & 1 & & Piyes & 1 \\
\hline Çarkifelek & 1 & & Hazine & 1 \\
\hline Çarpım tablosu & 1 & & Puzzle parçası & 1 \\
\hline Ütopya & 1 & & Yapboz & 1 \\
\hline Yabancı ülke & 1 & & Yaramaz bir çocuk & 1 \\
\hline Yabanc1 & 1 & & İlim kapisı & 1 \\
\hline Yalanlarla dolu bir yer & 1 & & Labirent & 1 \\
\hline Lunapark & 1 & & Yaşam koçu & 1 \\
\hline İlçe pazarı & 1 & & Sahne & 1 \\
\hline Tatmadığımız bir meyve & 1 & & Saldırı & 1 \\
\hline Tatil yeri & 1 & & Savaş & 1 \\
\hline Tecrübe & 1 & & İkinci hayat & 1 \\
\hline Terbiye edici ve yol gösterici & 1 & & $\begin{array}{l}\text { Yüksek ama ulaşma } \\
\text { ihtimali olan bir duvar }\end{array}$ & 1 \\
\hline Tohum & 1 & & Seyahat & 1 \\
\hline Toplanma kamp1 & 1 & & Simülasyon & 1 \\
\hline Trajedi & 1 & & Sokakta yaşamak & 1 \\
\hline
\end{tabular}




\begin{tabular}{llll}
\hline $\begin{array}{l}\text { Tüm akarsuları bünyesinde } \\
\text { toplayan bir deniz }\end{array}$ & 1 & $\begin{array}{l}\text { Yüksek düzeyde eğitimin } \\
\text { verildiği kurumlar }\end{array}$ & 1 \\
\hline Tiyatro sahnesi & 1 & Son durak & 1 \\
\hline Yeni taşındığımız bir ülke & 1 & Sonu olan özgürlük & 1 \\
\hline Yeniçă̆ & 1 & Zula & 1 \\
\hline Yeni doğulan bir ameliyathane & 1 & Yol ayrımı & 1 \\
\hline Yenidünya & 1 & Yeni ortam & 1 \\
\hline Laboratuvar & 1 & Lise & 1 \\
\hline Yazın yağan yağmur & 1 & Yuva & 1 \\
\hline Yemek yeme & 1 & Hızlandırılmış hayat kursu & 1 \\
\hline Zehir & 1 & Son basamak & 1 \\
\hline Hayatın bir kısmı & 1 & Fener & 1 \\
\hline 20 yıllık hayat tecrübesi & 1 & Büyük ev & 1 \\
\hline Hayat okulu & 1 & İkinci hayat & 1 \\
\hline Genel Toplam & & 312 & 423 \\
\hline
\end{tabular}

Tablo 2 incelendiğinde üniversite öğrencilerinin üniversite kavramına yönelik toplam 312 farklı ve geçerli metafor ürettiği görülmektedir. Üretilen metaforların 73'ü birden fazla öğrenci tarafından üretilmiştir. Üniversite kavramına yönelik en fazla üretilen metaforlar; hayat ( $\mathrm{f}=40)$, kitap $(\mathrm{f}=18)$, ev $(\mathrm{f}=11)$, bilim yuvası ( $\mathrm{f}=10)$, özgürlük $(\mathrm{f}=9)$, ağaç büyütme $(\mathrm{f}=7)$ dünya $(\mathrm{f}=7)$, şeklinde olmuştur.

\section{İkinci Alt Probleme İlişkin Bulgular}

\section{Tablo 3. Üniversite kavramının kategorilere göre dă̆ılımı}

\begin{tabular}{|c|c|c|c|}
\hline Kategori & Metaforlar & $\begin{array}{l}\text { Metafor } \\
\text { Sayıs1 }\end{array}$ & f \\
\hline $\begin{array}{l}\text { Her çeşit } \\
\text { insanın } \\
\text { olduğu yer }\end{array}$ & $\begin{array}{l}\text { (1): Her elementin yer aldığı bir maden, ressamın fırça darbeleri, pazar, Os- } \\
\text { manlı devleti, farklı harflerin bir araya gelerek oluşturduğu kelime, Dünya'nın } \\
\text { küçük hâli, disko topu gibi rengârenk, dibi kum çakıl dolu okyanus, müze, } \\
\text { çiftlik, mevsim, meyve bahçesi, çorba, memleket, medeniyet, küçük bir dünya, } \\
\text { bahar, kozmopolit, kıta, açık büfe, akvaryum, kazan, amazon ormanı, yabanc, } \\
\text { yabancı ülke, çarkıfelek, tımarhane, tüm akarsuları bünyesinde toplayan bir } \\
\text { deniz, toplanma kampı, ilçe pazarı, kozmopolit şehir, süpermarket, büyükşe- } \\
\text { hir, büyük ev, büyük bir sosyal kurum, insan pazarı, insan fabrikası, kâinat } \\
\text { (2): Hayvan çfftliği, orman, arıtma tesisi, hayvanat bahçesi } \\
\text { (4): Çiçek bahçesi, ülke, fabrika, bahçe, gökkuşağı } \\
\text { (5): Okyanus } \\
\text { (7): Dünya }\end{array}$ & 49 & 78 \\
\hline $\begin{array}{l}\text { Tecrübe } \\
\text { kazandıran } \\
\text { yer }\end{array}$ & $\begin{array}{l}\text { (1): Seyahat, ömür, öğretmen, olgunluk çağı, olgun ağaç, okuldan çok daha } \\
\text { fazlası, gezgin, kalkan, akademik başarı, tecrübe, hayatta olgunlaşma ve } \\
\text { yoğrulma evresi, yaşam koçu, yirmi yıllık hayat tecrübesi, hayat tecrübesi, } \\
\text { hayat okulu, hayatın bir kısmı, Sokakta yaşamak, gelişme, ayrı ülkeler, ayakta } \\
\text { durabilmek, yeni ortam, sorumluluk, puzzle parçası, yapboz, bulmaca, sosyal- } \\
\text { leşme, akıllı telefon } \\
\text { (7): Ağaç büyütme } \\
\text { (13): Hayat }\end{array}$ & 29 & 47 \\
\hline
\end{tabular}




\begin{tabular}{|c|c|c|c|}
\hline $\begin{array}{l}\text { Yeni bir } \\
\text { hayatın } \\
\text { başlangıcı } \\
\text { olan yer }\end{array}$ & $\begin{array}{l}\text { (1): Yol ayrımı, son durak, son basamak, ikinci hayat, hayata başlamak, hayata } \\
\text { atılan ilk adım, dünyaya yeniden gelmek, doğduğun ev, milat, meşale, merdi- } \\
\text { venin ilk basamağı, zirveye ulaşmaya yardımcı merdiven, kader, yeni doğulan } \\
\text { bir ameliyathane, yeniçağ, yeni alınmış bir ev, yeni taşındığımız bir ülke, } \\
\text { yaşam tarzı, yaşadığımız dünyanın dışında, başka bir evren, ilkokul, hayatın } \\
\text { yeni bir yolu, } \\
\text { (2): Yeni hayat, temiz bir sayfa, çıkmaz bir sokak, hayat } \\
\text { (3): Dönüm noktası, kitap } \\
\text { (5): Yol }\end{array}$ & 29 & 41 \\
\hline $\begin{array}{l}\text { Bilgilerin } \\
\text { kaynağı } \\
\text { olan ve } \\
\text { yayılan yer }\end{array}$ & $\begin{array}{l}\text { (1): Google, gezen bir kütüphane, nar, arama motoru, kadın, tohum, bilginin } \\
\text { ve kültürün birleştiği yer, bilgi merkezi, bilim kütüphanesi, bilim dünyası, } \\
\text { sinırsız kitap bulunan bir kütüphane, genel ağ, belediye, bilgi hazinesi, kalp } \\
\text { (3): Kitap } \\
\text { (4): Bilgisayar, ansiklopedi, deniz, kütüphane } \\
\text { (7): Bilim yuvası }\end{array}$ & 21 & 41 \\
\hline $\begin{array}{l}\text { Hayatına yön } \\
\text { verdiğin yer }\end{array}$ & $\begin{array}{l}\text { (1): Süreç, yolculuk, navigasyon, çımazdan önceki son tünel, yatırım, güzelli- } \\
\text { ğe ve kötülüğe açılan iki gizli kapı, beyin, kitap, hayat } \\
\text { (2): Kılavuz } \\
\text { (3): Harita } \\
\text { (4): Pusula, gelecek } \\
\text { (6): El feneri, merdiven basamakları }\end{array}$ & 15 & 34 \\
\hline Zor olan yer & $\begin{array}{l}\text { (1): İğneyle kuyu kazmak, engelli parkur, zorluklara temel atılan ilk yer, zor, } \\
\text { menfaat, açk cezaevi, kurtlar sofrası, bataklık, kardelen, yokuş, yaramaz bir } \\
\text { çocuk, çarpım tablosu, trajedi, tadı kötü yemek, cehennem, imtihan yeri, zehir, } \\
\text { hayvanat bahçesi, labirent } \\
\text { (2): Savaş Meydanı, hapishane } \\
\text { (3): Kafes, hayat } \\
\text { (4): Survivor }\end{array}$ & 24 & 33 \\
\hline $\begin{array}{l}\text { Emek vermen } \\
\text { gereken yer }\end{array}$ & $\begin{array}{l}\text { (1): Savaş, saldırı, para kazanma, maraton, marangoz, maden ocağı, başarılı } \\
\text { öğrenci, bahçe, hayat } \\
\text { (2): Tarım, merdiven } \\
\text { (3): Toprak, karınca yuvası } \\
\text { (4): Arıkovanı } \\
\text { (6): Tarla }\end{array}$ & 15 & 29 \\
\hline $\begin{array}{l}\text { Eğlenceli } \\
\text { olan yer }\end{array}$ & $\begin{array}{l}\text { (1): Sirk, palyaço, gül, gençlik festivali, festival, eğlencenin son aşaması, kum } \\
\text { saati, konser alanı, alışkanlık, kelebek, sosyal bir kafe, lunapark, çay, gökku- } \\
\text { şağı } \\
\text { (2): Kitap, yaşam, gezi } \\
\text { (3): Hayat } \\
\text { (4): Meyve }\end{array}$ & 18 & 25 \\
\hline $\begin{array}{l}\text { Gerçek hayatın } \\
\text { simülasyonu } \\
\text { olan yer }\end{array}$ & $\begin{array}{l}\text { (1): Simülasyon, hızlandırılmış hayat kursu, sahne, piyes, gelişim, kişilik testi, } \\
\text { antrenman, tiyatro sahnesi, hayatın gerçek yüzü, gerçek yaşam } \\
\text { (2): Hayatın kendisi, gerçekler, gonca gül } \\
\text { (3): Hayat sınavı } \\
\text { (5): Hayat }\end{array}$ & 15 & 24 \\
\hline $\begin{array}{l}\text { Bilgi sahibi } \\
\text { olduğun yer }\end{array}$ & $\begin{array}{l}\text { (1): Nebula, medrese, kurak bir toprağa özveri ile yetiştirilen ağaçlar, kumbara, } \\
\text { kuluçkadaki tavuk, kalem, ufka açlan bir kapı, gencin ikinci sosyal hayatı, boş } \\
\text { defter, bilgi, bilim, internet sitesi } \\
\text { (3): Kitap } \\
\text { (6): Hayat }\end{array}$ & 14 & 21 \\
\hline $\begin{array}{l}\text { Farklılaşıp yeni } \\
\text { bakış açıları } \\
\text { kazandığın yer }\end{array}$ & $\begin{array}{l}\text { (1): Dünyaya açılan yeni bir pencere, evrim, bakış açısı, kitap } \\
\text { (2): Anahtar, heykeltıraş } \\
\text { (3): Kendi benliğini tanıma }\end{array}$ & 9 & 21 \\
\hline
\end{tabular}




\begin{tabular}{|c|c|c|c|}
\hline & $\begin{array}{l}\text { (4): Ayna } \\
\text { (6): Hayat }\end{array}$ & & \\
\hline $\begin{array}{l}\text { Eşsiz ve güzel } \\
\text { olan yer }\end{array}$ & $\begin{array}{l}\text { (1): Yazın yağan yağmur, mükemmel, mutluluk, en rahat yıllar, bir çocuğun } \\
\text { elindeki dondurma, kâinat, gökkuşağı } \\
\text { (2): Hayatın en güzel ve rahat dönemi, çikolata, huzur, sevgi } \\
\text { (5): Aşk }\end{array}$ & 12 & 20 \\
\hline $\begin{array}{l}\text { Özgürlüğüun } \\
\text { başladığı yer }\end{array}$ & $\begin{array}{l}\text { (1): Sonu olan özgürlük, özgürlüğün başlangıcı, güvercin, gökyüzü, bağımsız } \\
\text { bir ülke, kuş, araba, cennet, kitap } \\
\text { (8): Özgürlük }\end{array}$ & 10 & 17 \\
\hline $\begin{array}{l}\text { Yaşam } \\
\text { alanı olan yer }\end{array}$ & $\begin{array}{l}\text { (1): Yuva } \\
\text { (2): Kuş yuvası } \\
\text { (3): Aile } \\
\text { (10): Ev }\end{array}$ & 4 & 16 \\
\hline $\begin{array}{l}\text { Aydınlanmanın } \\
\text { yaşandığı yer }\end{array}$ & $\begin{array}{l}\text { (1): Fener, eğitim yuvası, kitap, avize, ilim kapısı } \\
\text { (2): Işıı, güneş, deniz feneri } \\
\text { (3): Bilim yuvası }\end{array}$ & 9 & 14 \\
\hline $\begin{array}{l}\text { Değerli } \\
\text { ve mecburi } \\
\text { olan kurum }\end{array}$ & $\begin{array}{l}\text { (1): Altın bilezik, tatmadığımız bir meyve, kalp, gıda, mecburiyetten yediğin } \\
\text { yemek, asker ocağı, yemek yeme, ilaç, borç, kitap } \\
\text { (2): Su }\end{array}$ & 11 & 12 \\
\hline $\begin{array}{l}\text { Eğitici olan } \\
\text { kurum }\end{array}$ & $\begin{array}{l}\text { (1): Yüksek düzeyde eğitimin verildiği kurumlar, hazine, bahçıvan, ayrıcalığa } \\
\text { sahip olmak, ana, terbiye edici ve yol gösterici, kitap } \\
\text { (3): Meyve veren bir ağaç }\end{array}$ & 8 & 10 \\
\hline $\begin{array}{l}\text { Keşiflerin } \\
\text { yapıldığı yer }\end{array}$ & $\begin{array}{l}\text { (1): Hazine haritası, kimlik, yeni keşfedilmiş gezegen, laboratuvar, yenidünya } \\
\text { (2): Keşfedilmemiş gezegen } \\
\text { (3): Kamp alanı }\end{array}$ & 7 & 10 \\
\hline $\begin{array}{l}\text { Hayal kırıklı- } \\
\text { ğının yaşandığı } \\
\text { yer }\end{array}$ & $\begin{array}{l}\text { (1): Pembe hayaller, pembe hayallerle gidilen ama hayattaki her şeyde olduğu } \\
\text { gibi hayal kırıklıklarına uğranan bir mekân, hayal kırıklığı, dipsiz kuyu, çölde } \\
\text { bir serap, tatil yeri, insan, yalanlarla dolu bir yer, bukalemun }\end{array}$ & 9 & 9 \\
\hline $\begin{array}{l}\text { Hayallerin } \\
\text { gerçekleştiği } \\
\text { yer }\end{array}$ & $\begin{array}{l}\text { (1): Hayallere giden yolda durağa gelen otobüs, hayal, fırsatları değerlendir- } \\
\text { menin en iyi ortamı, ütopya, umut } \\
\text { (2): Tren, rüya }\end{array}$ & 5 & 9 \\
\hline $\begin{array}{l}\text { Heyecanın } \\
\text { yaşandığı yer }\end{array}$ & (1): Adrenalin, fantastik-gerilim filmi, muz, macera & 4 & 4 \\
\hline $\begin{array}{l}\text { Maddi } \\
\text { zorlukların } \\
\text { yaşandığı yer }\end{array}$ & $\begin{array}{l}\text { (1): Fakirlik, kapitalist sistem, yüksek ama ulaşma ihtimali zor olan bir duvar, } \\
\text { dağın zirvesi }\end{array}$ & 4 & 4 \\
\hline $\begin{array}{lr}\text { Ezberi } & \text { zorunlu } \\
\text { k1lan } & \text { sıradan } \\
\text { bir yer } & \end{array}$ & $\begin{array}{l}\text { (1): Papağan, okul, lise } \\
\text { (2): Cezaevi }\end{array}$ & 2 & 4 \\
\hline $\begin{array}{l}\text { Gizliliğin } \\
\text { olduğu yer }\end{array}$ & (1): Zula, panaptikon, gizemli bir yer & 3 & 3 \\
\hline \multirow[t]{2}{*}{$\begin{array}{l}\text { Boşluğa düşü- } \\
\text { len yer yer }\end{array}$} & $\begin{array}{l}\text { (1): Boş } \\
\text { (2): Uzay }\end{array}$ & 2 & 3 \\
\hline & Toplam öğrenci sayısı & 539 & \\
\hline
\end{tabular}

Tablo 3'te üniversite kavramına yönelik metaforların oluşturduğu kategoriler sunulmuştur. Bu tabloya göre toplam öğrenci sayısına göre en çok metafor içeren ilk üç kategori; "Her çeşit insanın olduğu yer" (f=78), Tecrübe kazandığın yer" ( $\mathrm{f}=47$ ) ve "Yeni bir hayatın başlangıcı olan yer" (f=41) "olduğu görülmektedir. 


\section{Her çeşit insanın olduğu yer}

“Üniversite her elementin yer aldığı bir madendir, çünkü neyi aradığın ne için çalıştı̆̆ın hayatının geri kalanım belirler (280E)."

"Üniversite Osmanl devleti gibidir, çünkü bütün ırklardan insanlar vardır (364E)."

\section{Tecrübe kazandtran yer}

"Üniversite bir öğretmen gibidir, çünkü sana sorumluluk almayı, hayatın zorluklaronı ve ailenden uzak tek başına yaşayabilmeyi öğretir (228E)."

"Üniversite hayat okulu gibidir, çünkü karakter gelişimini tamamlamıs ya da tamamlamak üzere olan her çeşit insan ve onlardan öğrenilecek çok şey var (544K)."

\section{Yeni bir hayatın başlangıcı olan yer}

"Üniversite ikinci hayat gibidir, çünkü birçok kişi için dönüm noktasıdır ve asıl gerçeklerle yüzleşme olarak tanımlyyorum (549K)."

"Üniversite yeni başlayan bir hayat gibidir, çünkü tertemiz ve yeni bir sayfayı doldurmaya başlamaktadır (251K)."

"Üniversite benim için yeni açılmış tertemiz bir sayfa gibidir, çünkü adım attığın ilk günden itibaren yeni insanlar, farklı şehirler, farklı tecrübeler, yaşantı tecrübesi ve yeni sorumluluklar kazandirnyor insana. Ayrnca bunlar benim açtığım o sayfaya birer anı olarak yazılıyor (415E)."

\section{Bilgilerin kaynă̆ı olan ve yayıldığı yer}

"Üniversite Google gibidir, çünkü aradı̆̆ın her şeyi bulabilirsin (454K)."

"Üniversite kitap gibidir, çünkü okudukça ufkunu açan, yeni bilgiler kazandlran, yol gösteren ve gelecek nesille aktarabileceğin bilgi topluluğudur (33K)."

"Üniversite kütüphane gibidir, çünkü bulmak istediğimiz her türlü bilgi mevcuttur. Önemli olan aramaktır (166K)."

\section{Hayatına yön verdiğin yer}

"Üniversite senin yolunu bulmaya çalşan bir harita gibidir, çünkü Üniversite insanın hayatın bir nebze de olsa belirler (98K)."

"Üniversite pusula gibidir, çünkü kişinin kendi yolunu bulup çizdiği ve o yolda kendini tanıdığı bir yolculuktur (90K)." 


\section{Zor olan yer}

"Üniversite okumak iğneyle kuyu kazmak gibi çünkü her anlamda mükemmel olmak zorundasin ve ince ince inşa etmelisin hayatını (47K)."

"Üniversite survivor gibidir, çünkü hem hayatta kalmak zorundasın hem de rakiplerini elemek zorundasin (140K)."

\section{Emek vermen gereken yer}

“Üniversite tarma benzer, çünkü uygun topră̆a uygun tohum ekeceksin, emek vereceksin, emek verirsen karşılık verir (167K)."

"Üniversite karınca yuvası gibidir, çünkü daima çok çalşman gerekir (168K)."

\section{Eğlenceli olan yer}

"Üniversite gençlik festivali gibidir, çünkü festivale insanlar hem eğlenmek hem de yeni bir şeyler için giderler (223K)."

"Üniversite kocaman sosyal bir kafe gibidir, çünkü oturup sohbet de edebilirsin bir şeyler öğrenerek, oyunda oynayabilirsin. Çünkü gençler arasinda her türlü ĕ̆lence ve bilgi olur (208K)."

\section{Gerçek hayatın simülasyonu olan yer}

"Üniversite simülasyon gibidir, çünkü hayatın özetini yaşadığın bir mecradır (253K)."

"Üniversite antrenman gibidir, çünkü hayat mücadelesine hazırlar (207E)."

\section{Bilgi sahibi olduğun yer}

"Üniversite bir kitap gibidir, çünkü her okuduğunda sana bir şey katar. Kimi zaman bilgi, kimi zaman tecrübe, kimi zaman da kültürdür (16K)."

"Üniversite kumbaraya benzemektedir, çünkü anl, bilgi, arkadaş biriktirirsin (118K)."

\section{Farklılaşıp yeni bakış açıları kazandığın yer}

“Üniversite bakış açısı gibidir, çünkü Üniversite aklı, fikri ve vicdanı hür bireylerin ön yargılardan armmış ve yeteneklerini pekiştirdiği yerlerdir (479K)."

"Üniversite hayat gibidir, çünkü Üniversite hayata karşı bakış açımızı değiştirir (48K)." 


\section{Eşsiz ve güzel olan yer}

"Üniversite yazın yağan yağmur gibidir, çünkü o mevsimde eşsiz ve güzeldir (444K)."

"Üniversite hayatın en güzel dönemi gibidir, çünkü belli bir işe başlamadan önce özgürce davranabildiğin bir yerdir (15E)."

\section{Özgürlüğ̈̈n başladı̆̆ı yer}

"Üniversite özgürlü̆̆̈̈n başlangıcıdır, çünkü insan üniversitede özgürlüğ̈̈nü fark eder (26E)."

"Üniversite gökyüzüne benzemektedir, çünkü asıl özgürlük orada başlamaktadır (318K)."

\section{Yaşam alanı olan yer}

"Üniversite yuva gibidir, çünkü yeni yaşam yerimizdir (527K)."

"Üniversite aile gibidir, çünkü sıcak bir yuva sunmaktadır (354K)."

\section{Aydınlanmanın yaşandığı yer}

"Üniversite güneş gibidir, çünkü günümüzü aydınlatır, bize yeniden bir doğuş sağlar (14K)."

"Üniversite bir avize gibi gibidir, çünkü orada karalk kaldığımı günler aydınlanır geleceğimize ışık tutarak geleceğimizi yön vermemizde yardımcı olur (100E)."

\section{Değerli ve mecburi olan kurum}

"Üniversite gıda gibidir, çünkü gıdasız insan sağhlksız ve ölüme mahkûmdur (386K)."

"Üniversite altın bilezik gibidir, çünkü altın bilezik bir güvencedir. Yarnndır, umuttur (390K)."

\section{Eğitici olan kurum}

Üniversite yüksek düzeyde eğitimin verildiği kurumlar gibidir, çünkü mesleğin öğrenim aşamasıdır (526K)."

Üniversite terbiye edici ve yol gösterici gibidir, çünkü yol gösterici olmadan ışık dahi faydasiz olur (217K)." 


\section{Keşiflerin yapıldı̆̆ı yer}

"Üniversite yeni keşfedilmiş gezegen gibidir, çünkü her şeyiyle öğrenmek istersin (257E)."

"Üniversite laboratuvar gibidir, çünkü kendini keşfetmeni să̆lar (197K)."

\section{Hayal kırnklı̆̆ının yaşandiğı yer}

"Üniversite " çölde bir serap " gibidir, çünkü uzaktan çok güzel görünür ama yakınlaştıkça ve sonuna geldikçe çok da güzel olmadığ ı görünür (221K)."

"Üniversite pembe hayaller gibidir, çünkü hayal kırnklı̆̆ına uğranan mekândır bence günümüzde (426K)."

\section{Hayallerin gerçekleştiği yer}

"Üniversite hayallere giden yolda dură̆a gelen otobüs gibidir, çünkü o durakta başına ne geleceği gidebileceğin yere varabileceğin çokta belli değildir (433K)."

"Üniversite firsatlarn değerlendirmenin en iyi ortamı gibidir, çünkü algının ve yaşın en açık ve en güzel olduğu zamanlardır (29E)."

\section{Heyecanin yaşandiğı yer}

"Üniversite adrenalin gibidir, çünkü hem heyecanlı hem de streslidir, tüm duygularl barndirır (187K)."

"Üniversite fantastik-gerilim filmi gibidir, çünkü acısıyla tatlısıyla yaşanılan üniversite hayatı bir film tadındadır (163K)."

\section{Maddi zorlukların yaşandığı yer}

“Üniversite fakirlik gibidir, çünkü her öğrenci burs alamıyor (511K)."

"Üniversite kapitalist sisteme hizmet eden köle yuvaları gibidir, çünkü her döneminde yarış halinde olduğumuz yetiştirilen bireylerin toplumda nitelikleriyle var olmasidır (319K)."

\section{Ezberi zorunlu kılan siradan bir yer}

“Üniversite papağana benzer, çünkü ezbere dayah bir sistemdir (327K)."

"Üniversite lise gibidir, çünkü aynısını yaşıyoruz sanki (504K)."

\section{Gizliliğin olduğu yer}

"Üniversite zula gibidir, çünkü aileden gizli sakh birçok şey barındırı (46K)." 
“Üniversite panaptikona benzer, çünkü içeridekiler dışarıdan nasıl göründüklerini bilmezler (294K)."

\section{Boşluğa dü̈sülen yer yer}

“Üniversite uzay gibidir, çünkü bitince boşluğa düşersin (22K).”

\section{Tartışma ve Sonuç}

üniversite öğrencilerinin üniversite kavramına yönelik toplam 312 farklı ve geçerli metafor ürettiği görülmektedir. Üretilen metaforların 73'ü birden fazla öğrenci tarafından üretilmiştir.Üniversite kavramına yönelik en fazla üretilen metaforlar; hayat $(\mathrm{f}=40)$, kitap $(\mathrm{f}=18)$, ev $(\mathrm{f}=11)$, bilim yuvası $(\mathrm{f}=10)$, özgürlük ( $\mathrm{f}=9)$, ağaç büyütme $(\mathrm{f}=7)$ dünya $(\mathrm{f}=7)$, olmuştur. Cinsiyet değişkenine göre incelendiğinde ise kız öğrencilerin 423, erkek öğrencilerin 116 metafor ürettiği görülmüştür. Araştırma da en çok metafor içeren ilk üç kategori; "Her çeşit insanın olduğu yer" ( $\mathrm{f}=78)$, Tecrübe kazandığın yer" $(\mathrm{f}=47)$ ve "Yeni bir hayatın başlangıcı olan yer" ( $\mathrm{f}=41)$ "olduğu görülmektedir.

Araştırma sonuçlarına göre üniversite öğrencilerinin oluşturmuş olduğu kategorilerden 20'si olumlu 5'i olumsuz olmak üzere 25 kategori altında toplandığ1 görülmüştür. Literatürde yapılan araştırmalar incelendiğinde; Demirtaş ve Çoban (2011) tarafından yapılmış araştırma da üniversite öğrencilerinin, üniversite ile ilgili sahip oldukları metaforların 9'u olumlu, 5'i olumsuz olmak üzere 14 kategori altında toplandığı ifade edilmiştir.

Öğrencilerin ürettiği metaforlar frekans sayısı bakımından sırasıyla; her çeşit insanın olduğu yer, tecrübe kazandıran yer, yeni bir hayatın başlangıcı olan yer, bilgilerin kaynağı olan ve yayıldığ 1 yer, hayatına yön verdiğin yer, zor olan yer, emek vermen gereken yer, eğlenceli olan yer, gerçek hayatın simülasyonu olan yer, bilgi sahibi olduğun yer, farklılaşıp yeni bakış açıları kazandığın yer, eşsiz ve güzel olan yer, özgürlügüun başladığı yer, yaşam alanı olan yer, aydınlanmanın yaşandığı yer, değerli ve mecburi olan kurum, eğitici olan kurum, keşiflerin yapıldığı yer, hayal kırıklığının yaşandığı yer, hayallerin gerçekleştiği yer, heyecanın yaşandığı yer, maddi zorlukların yaşandığ1 yer, ezberi zorunlu kılan sıradan bir yer, gizliliğin olduğu yer, boşluğa düşülen yer yer gibi toplam 25 kategori başlığı altında yer aldığı görülmüştür. 
Araştırma da ortaya çıan ilk kategori incelendiğinde; üniversitelerin her çeşit insanın olduğu kozmopolit bir yer olarak ifade edildiği görülmektedir. Bu durum "Her çeşit insanın olduğu yer" kategorisi altında ( $f=1)$ : Her elementin yer aldığı bir maden, ressamın fırça darbeleri, pazar, Osmanlı devleti, farklı harflerin bir araya gelerek oluşturduğu kelime, Dünya'nın küçük hâli, disko topu gibi rengârenk, dibi kum çakıl dolu okyanus, müze, çiftlik, mevsim, meyve bahçesi, çorba, memleket, medeniyet, küçük bir dünya, bahar, kozmopolit, kıta, açık büfe, akvaryum, kazan, amazon ormanı, yabancı, yabancı ülke, çarkıfelek, tımarhane, tüm akarsuları bünyesinde toplayan bir deniz, toplanma kampı, ilçe pazarı, kozmopolit şehir, süpermarket, büyükşehir, büyük ev, büyük bir sosyal kurum, insan pazarı, insan fabrikasl, kâinat, (f=2): Hayvan çiftliği, orman, arıtma tesisi, hayvanat bahçesi, ( $f=4$ ): Çiçek bahçesi, ülke, fabrika, bahçe, gökkuşağı, (f=5): Okyanus, (f=7): Dünya gibi metaforlar aracılığıyla yansıtıldığı görülmüş̧ür. Bu verilerden hareketle Bingöl Üniversitesinin eğitim amaçlı ülkenin her tarafından öğrencileri çektiği ve sürekli bir sirkülasyonun olduğu şeklinde değerlendirilebilir.

Araştırma da ortaya çıkan ikinci kategori incelendiğinde; üniversitelerin tecrübe kazandıran yer olarak ifade edildiği görülmektedir. Bu durum "tecrübe kazandıran yer" kategorisi altında $(\mathbf{f}=\mathbf{1})$ : seyahat, ömür, öğretmen, olgunluk çağı, olgun ağaç, okuldan çok daha fazlası, gezgin, kalkan, akademik başarı, tecrübe, hayatta olgunlaşma ve yoğrulma evresi, yaşam koçu, yirmi yıllık hayat tecrübesi, hayat tecrübesi, hayat okulu, hayatın bir kısm1, sokakta yaşamak, gelişme, ayrı ülkeler, ayakta durabilmek, yeni ortam, sorumluluk, puzzle parçası, yapboz, bulmaca, sosyalleşme, akıllı telefon, ( $f=7$ ): ağaç büyütme ( $(=\mathbf{= 1 3})$ : hayat gibi metaforlar aracılığıyla yansıtıldığı görülmüştür. Bu verilerden hareketle öğrencilerin üniversiteyi tecrübe ve deneyim kazandığı yer olarak gördükleri şeklinde ifade edilebilir. Üniversite kavramının bu özelliğinin ortaya çıkmış olması üniversitenin tecrübe, deneyim ve yaşantıya ilişkin misyonunu yerine getirdiği şeklinde yorumlanabilir.

\section{EXTENDED ABSTRACT}




\title{
University Concept in the Eyes of University Students
}

\author{
Nesip Demirbilek \\ Bingöl Üniversitesi
}

Access to higher education is one of the main problems related to higher education in our country. Especially since the mid-20th century, as stated in the human capital theory, the belief that universities have a high level of influence on increasing social and individual development has increased the demand for universities (Özoğlu, 2011). In our country, especially in the last twenty years, the number of public and foundation higher education organizations has increased.

In addition, while the importance and interest gave by the society to the university gradually increases, it is said that the problems experienced in the universities are increasing with each passing day (Demirtaş \& Çoban, 2011). In this context, it is important to conduct metaphor studies in order to better understand the perception that the concept of university creates in students' minds and thus to explain it better. The aim of the study is to reveal how university students conceptualize their thoughts about the concept of the university through metaphors.

In the study, the phenomenological design, one of the qualitative research designs, was used as the meanings attributed to the university concept were examined in depth in line with the opinions of university students studying in various departments of Bingöl University. Phenomenology pattern is used to illuminate the cases that we are aware of but want to determine in-depth and with their reasons (Yıldırım and Şimşek, 2013).

In the research, a form consisting of two parts was created online. In the first part, there is a personal information form asking about demographic characteristics. In the second part, they were asked to complete the metaphor sentence. In addition, some examples are given by explaining the metaphors of some concepts in this section. Accordingly, participants were asked to create a single metaphor and state the reason (K1lcan, 2017). The prepared forms were sent by e-mail. The prepared form was kept accessible for one month. In the research, 549 university students studying in the last 
year of the faculties of Bingol University were reached. However, ten forms that form erroneous or that do not form metaphors regarding the concept of academic achievement were eliminated. As a result, the participants consisted of 539 people.

Content analysis was used in the analysis of the data obtained in the study. The data collected in content analysis are analyzed in four stages: Coding and sorting, category development stage, validation and reliability stage, and interpretation of the findings (Saban, 2008).

According to the results of the research, the students produced a total of 312 different and valid metaphors for the concept of university. 73 of the produced metaphors were produced by more than one student. The most produced metaphors for the concept of university are life $(f=40)$, book $(f=$ $18)$, house $(f=11)$, science home $(f=10)$, freedom $(f=9)$, tree growing $(f=7)$ world $(f=7)$ has become. When analyzed according to gender variable, it was seen that female students produced 423 metaphors and male students produced 116 metaphors. The first three categories that contain the most metaphors in research are; "The place where all kinds of people are" $(f=78)$, the place where you gain experience " $(\mathrm{f}=47)$ and " the place where a new life starts " $(\mathrm{f}=41)^{\prime \prime}$.

According to the results of the research, it was seen that university students were grouped under 25 categories, 20 of which are positive and 5 of which are negative. When the studies in the literature are examined; In the research conducted by Demirtaş and Çoban (2011), it was stated that the metaphors university students have about the university were grouped under 14 categories, 9 of which are positive and 5 of which are negative.

The metaphors produced by the students were respectively; the place where all kinds of people are, the place that gives experience, the place where a new life begins, the source and spread of information, the place where you direct your life, the difficult place, the place where you have to work, the place where it is fun, the place that is a simulation of real life, the knowledgeable where you are, where you become different and gain new perspectives, the place that is unique and beautiful, the place where freedom begins, the place where enlightenment takes place, the valuable and obligatory institution, the institution that is educational, the place where discoveries are made, the place where the disappointment comes true, place, place of excitement, place of financial difficulties, an ordinary place 
requiring memorization, where there is privacy, and the place where there is a gap.

\section{Kaynakça / References}

Açıkgöz, Ö. (2012). Yükseköğretim üzerine bir değerlendirme: yeniden yapılanma sürecinde bir sistem önerisine giriş. Yükseköğretim ve Bilim Dergisi, 2(Ek say1), 11-17.

Antalyall, Ö. (2007). Tarihsel süreç içerisinde üniversite misyonlarının oluşumu. Süleyman Demirel Üniversitesi Sosyal Bilimler Dergisi, 6, 25-40

Çetinsaya, G. (2014). Büyüme, kalite, uluslararasılaşma: Türkiye yükseköğretimi için bir yol haritası. Eskişehir: Anadolu Üniversitesi Basımevi.

Demirtaş, H., ve Çoban, D. (2014). Üniversite öğrencilerinin, üniversite ve fakülte kavramlarına ilişkin metaforları İnönü Üniversitesi Örneği. On dokuz Mayıs University Journal of Education, 33(1).

Kılcan, B. (2017). Metafor ve eğitimde metaforik çalışmalar için bir uygulama rehberi. Ankara: Pegem Akademi Yayıncilk.

Kıllı̧, R. (1999). Türkiye yükseköğretiminin kapsamı ve tarihsel gelişimi. Sosyal Bilimler Dergisi, 289-310.

Kurt, T. ve Gümüş, S. (2015). Dünyada yükseköğretimin finansmanına ilişkin eğilimler ve Türkiye için öneriler. Yükseköğretim ve Bilim Dergisi, 5(1), 14-26.

Mayring, P., Gümüş, A., ve Durgun, S. M. (2011). Nitel sosyal araştırmaya giriş: nitel düşünce için bir rehber. Bilgesu Yayıncllk.

Miles, M. B., \& Huberman, A. M. (1994). Qualitative data analysis: An expanded sourcebook. Sage.

Ortaş, İ. (2004). Üniversite özerkliği nedir? Bilim, Eğitim ve Diuşünce Dergisi, 4(1), 1- 7.

Özoğlu, M. (2011). Statükodan değişime: 21. yüzyılın başında Türkiye'de yükseköğretim. B. GÜR (ed.), 2000'li Yallarda Türkiye'de eğitim içinde (s. 125-161). İstanbul: Meydan Yayıncllk.

Patton, M. Q. (2014). Qualitative research \& evaluation methods: Integrating theory and practice. Sage publications.

Saban, A. (2008). Okula ilişkin metaforlar. Kuram ve Uygulamada Eğitim Yönetimi Dergisi, 14(3), 459-496.

Sönmez, V. ve Alacapınar, F. G. (2011). Örneklendirilmiş bilimsel araştırma yöntemleri [Exemplified scientific research methods]. Ankara: ANI Yayıncllk.

Şahin, İ., Zoraloğlu, Y. R. ve Furat, N. Ş. (2011). Üniversite öğrencilerinin yaşam amaçları, eğitsel hedefleri, üniversite öğreniminden beklentileri ve memnuniyet durumları. Kuram ve Uygulamada Eğitim Yönetimi. 17(3), 429- 452. 
Timur, T. (2000). Toplumsal değişme ve üniversiteler, Ankara: İmge Kitabevi.

Uysal, D. ve Ersun Aydemir, E. (2016). Türkiye'de yükseköğretim kavramı ve yükseköğretimin istihdam ve ekonomiye etkisinin analizi. Selçuk Üniversitesi Sosyal Bilimler Enstitüsü Dergisi, 35, 275-284.

Yaman, E., Mermer, E. Ç., ve Mutlugil, S. (2009). İlköğretim okulu öğrencilerinin etik davranışlara ilişkin görüşleri: Nitel bir araştırma. Değerler Eğitimi Dergisi, 7(17), 93-108.

Yıldırım, A., ve Şimşek, H. (2013). Sosyal bilimlerde nitel araştırma yöntemleri.(9. Genişletilmiş Baskı) Ankara: Seçkin Yayınevi.

\section{Kaynakça Bilgisi / Citation Information}

Demirbilek, N. (2020). Üniversite öğrencilerinin gözüyle üniversite kavramı. OPUS-Uluslararası Toplum Araştırmaları Dergisi, 16(Eğitim ve Toplum Özel Sayıs1), 5585-5607. DOI: 10.26466/opus.786247 